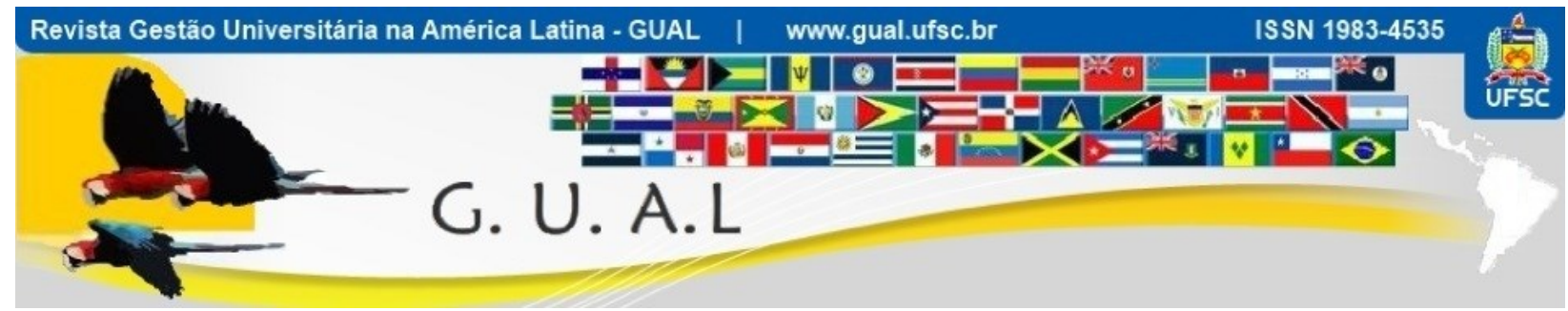

DOI: http://dx.doi.org/10.5007/1983-4535.2020v13n3p24

\title{
AS ESTRATÉGIAS COM “EXTREMA UTILIZAÇÃO” DOS PROGRAMAS DE STRICTO SENSU DAS INSTITUIÇÕES DO BRASIL DA ÁREA DE ADMINISTRAÇÃO PÚBLICA E DE EMPRESAS, CIÊNCIAS CONTÁBEIS E TURISMO FRENTE AOS CENÁRIOS PROSPECTADOS PARA O PERÍODO DE 2019 A 2030
}

\section{THE "EXTREME USE" STRATEGIES OF THE STRICTO SENSU PROGRAMS OF THE BRAZILIAN INSTITUTIONS IN THE PUBLIC ADMINISTRATION AND BUSINESS, ACCOUNTING AND TOURISM AREAS IN RELATION TO THE PROSPECTIVE SCENARIOS FOR THE PERIOD FROM 2019 TO 2030}

Henrique César Melo Ribeiro, Doutor
https://orcid.org/0000-0002-0704-1812
hemribeiro@gmail.com
Universidade Federal do Delta do Parnaíba $\mid$ Curso de Administração
Fortaleza | Ceará | Brasil

Sérgio Henrique Arruda Cavalcante Forte, Doutor https://orcid.org/0000-0002-8406-0910 sergioforte@unifor.br Universidade de Fortaleza | Programa de Pós-Graduação em Administração Fortaleza | Ceará | Brasil

Recebido em 17/maio/2019

Aprovado em 23/abril/2020

Publicado em 01/setembro/2020

Sistema de Avaliação: Double Blind Review

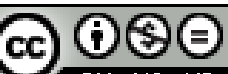

Esta obra está sob uma Licença Creative Commons Atribuição-Uso. 


\title{
RESUMO
}

O objetivo deste estudo foi identificar as estratégias com "extrema utilização" dos Programas de Stricto Sensu das Instituições de Ensino Superior do Brasil da área de Administração Pública e de Empresas, Ciências Contábeis e Turismo frente aos cenários prospectados para o período de 2019 a 2030. Utilizou-se a metodologia de cenários sugerida por Blanning e Reinig. Os resultados mostram que das estratégias nos cenários otimista e realista, enfatiza-se o item "fomentar a qualidade das teses e das dissertações". Quanto ao cenário pessimista, realça-se a estratégia "reduzir custos (pessoal, despesas administrativas, enxugamento da estrutura organizacional)", constatando assim sua importância, como estratégia a ser seguida em cenários incertos. A contribuição que este estudo acarreta para a literatura acadêmica da área é trazer em pauta um alargado e robusto número de estratégias que poderão viabilizar contribuições importantes para as instituições e seus respectivos programas de pós-graduação stricto sensu da área de administração, contabilidade e turismo em cenários de incertezas e desafios em decorrência da competitividade, perseguindo e alçando a posteriori melhores níveis de performance organizacional.

Palavras-chave: Prospecção de Cenários. Programas de stricto sensu do Brasil. Área de Administração Pública e de Empresas, Ciências Contábeis e Turismo. Estratégias. Extrema Utilização.

\begin{abstract}
The objective of this study was to identify the "extreme use" strategies of the Stricto Sensu Programs of the Higher Education Institutions of Brazil in the Public Administration and Business, Accounting and Tourism areas against the scenarios for the period 2019 to 2030. We used the scenario methodology suggested by Blanning and Reinig. The results show that from the strategies in the optimistic and realistic scenarios, the emphasis is on "promoting the quality of theses and dissertations". As for the pessimistic scenario, the strategy "reduce costs (personnel, administrative expenses, downsizing of the organizational structure)" is highlighted, thus confirming its importance as a strategy to be followed in uncertain scenarios. The contribution that this study brings to the academic literature of the area is to bring into the agenda a broad and robust number of strategies that could make important contributions to the institutions and their respective stricto sensu postgraduate programs in the area of administration, accounting and tourism in scenarios of uncertainties and challenges as a result of competitiveness, pursuing and raising a posteriori better levels of organizational performance.
\end{abstract}

Keywords: Prospecting Scenarios. Stricto sensu Programs in Brazil. Area of Public Administration and of Companies, Accounting Sciences and Tourism. Strategies. Extreme Use. 


\section{INTRODUÇÃO}

Os cenários são veículos para a exploração das causas e resultados da interação entre as forças no ambiente contextual que impulsionam o futuro do desdobramento no contexto da questão focal (BRADFIELD; CAIRNS; WRIGHT, 2015). Em outras palavras, são exposições, realçadas em hipóteses aceitáveis, do que poderá ocorrer, admitindo, com isso, se tomar e apoiar decisões estratégicas, que sejam admissíveis para todos os futuros presumíveis, possibilitando a prospecção de cenários e suas respectivas análises (SOUSA; FORTE; OLIVEIRA, 2012). A prospecção de cenários força os gestores a pensar no futuro (ITHNIN et al., 2018) e formular situações futuras, analisando decisões e o que poderia ser feito, e não o que foi realizado, possibilitando empreender diferentes unidades e modelos de negócios para o futuro.

Alicerçando em uma busca criativa (SOUSA; FORTE; OLIVEIRA, 2012), de recursos (BARNEY, 1991; WERNERFELT, 1984), de opções estratégicas (RAM; MONTIBELLER; MORTON, 2011), de intervenções estratégicas (HODGKINSON; HEALEY, 2008), buscando estratégias competitivas (PORTER, 1980). O persistente e recente interesse significativamente maior em prospecção de cenários, oferece insights relevantes para estender ideias de complexidade além da academia e investigação, em esferas mais amplas de estratégia corporativa e gerenciamento de mudança (WILKINSON; KUPERS; MANGALAGIU, 2013).

A pesquisa de prospecção de cenários vem se tornando um instrumento valoroso para a educação superior (RIECKMANN, 2012) nas Instituições de Ensino Superior - IESs públicas e privadas do Brasil, pois contribui para a estratégia dos programas de pósgraduação, sobretudo para o planejamento estratégico (LINDGREN; BANDHOLD, 2003) alicerçado em uma investigação prospectiva de cenários/futuros prováveis/preferidos (HICKS; GIDLEY, 2012; ITHNIN et al., 2018), sendo possível, assim, influenciar nas tomadas de decisões e nas escolhas de estratégias competitivas (PORTER, 1980).

Heinzen e Marinho (2019) propuseram um modelo para alinhava formulação e implementação da estratégia em IES. Ressalta-se que, para a construção do modelo, foi utilizado a metodologia de cenário como input e considerados os principais elementos que possibilitam a formulação e implementação da estratégia. Os autores concluíram que a metodologia de cenário é um instrumento relevante para a gestão estratégica das IES. 
O foco desta pesquisa, após ser realizado um levantamento da análise de cenários relacionados à área de educação, mas propriamente da pós-graduação, em especial do stricto sensu, constatou-se que poucos estudos investigaram a aplicação e o uso dos métodos de cenários no setor da educação superior (HEINZEN, 2015). Justifica-se, também, a realização deste estudo, ao entender, compreender e constatar que estudos nacionais, tais como os de Cenários, ainda são embrionários no contexto acadêmico internacional (HADDAD et al., 2017).

Isto posto, a questão de pesquisa que alicerçou e norteou este estudo foi: Quais as estratégias com "extrema utilização" dos Programas de Stricto Sensu das Instituições de Ensino Superior do Brasil da área de Administração Pública e de Empresas, Ciências Contábeis e Turismo frente aos cenários prospectados para o período de 2019 a 2030 ? E o objetivo foi: identificar as estratégias com "extrema utilização" dos Programas de Stricto Sensu das Instituições de Ensino Superior do Brasil da área de Administração Pública e de Empresas, Ciências Contábeis e Turismo frente aos cenários prospectados para o período de 2019 a 2030. A escolha da temporalidade de 12 anos deu-se sobretudo em virtude desta abranger o período de três governos do Brasil (2019-2022, 2023-2026 e 2027-2030).

Isto posto, ressalta-se que a importância pelo tema Cenário apareceu em razão de se ter observado que investigações sobre prospecção de cenários terem sido realizadas em diferentes países, e o Brasil está entre eles, relacionando o citado tema com setores de atividade, como por exemplo, setor: financeiro, combustível, ensino superior, turismo, construção civil, automobilístico. Diante do exposto, surge a possibilidade de unir o estudo de cenários com o ensino dos Programas de Stricto Sensu das IESs públicas e particulares do Brasil.

Acredita-se que este estudo poderá suprir as demandas de um cenário melhor para os programas stricto sensu das IESs públicas e privadas do Brasil da área de Administração Pública e de Empresas, Ciências Contábeis e Turismo mediante a oferta das metodologias e das ferramentas que a literatura disponibiliza, além da identificação e realce dos eventoschaves que possam ter elevado impacto na mencionada área do conhecimento.

Em suma, pretende-se, assim, com esta pesquisa, oferecer uma contribuição para o Brasil chegar, o mais perto possível, dos cenários desejados (POLESI, 2006), para os Programas Stricto Sensu das IESs públicas e privadas da área de Administração Pública e de Empresas, Ciências Contábeis e Turismo. Como consequência disso, cabe proporcionar, a 
posteriori, ao Brasil um futuro economicamente dinâmico, socialmente justo, regulado por um regime democrático eficaz e substantivo e com inserção internacional coerente em especial na área de educação (POLESI, 2006).

\section{REFERENCIAL TEÓRICO}

Esta seção abordará os assuntos: prospecção de cenários, estratégias e pós-graduação no Brasil.

\subsection{PROSPECÇÃO DE CENÁRIOS}

Prospecção remete à estratégia (GODET, 2010) e essa estratégia é baseada em cenários (MOORCROFT, 2015). Diante disso, entende-se que o planejamento de cenários é uma ferramenta de cenários que é amplamente utilizado no planejamento estratégico (BOWMAN, 2016). Neste panorama, versa-se que a atitude prospectiva não espera pela alteração e depois reage, ela visa dominar a mudança esperada (preatividade) e induzir uma transformação desejada (proatividade). Preatividade é o que orienta todas as abordagens para futuros estudos, previsão, planejamento de cenários e prospecção. A proatividade é mais voluntarista, e visa trazer as modificações desejadas por meio do planejamento estratégico. O que se força a pensar: é importante repensar os problemas para avançar (GODET, 2010).

Dentre os métodos desenvolvidos para assessorar o pensamento estratégico e prospectivo, a metodologia de cenários (BENEDETTI; VIDOR, 2016) contraiu uma particular popularidade, pois, de maneira geral, é visto como uma ferramenta útil para a análise prospectiva e, assim, um instrumento de auxílio ao processo decisório (OLIVEIRA; FORTE, 2009). O planejamento de cenários lida com o domínio do possível e do provável, ou seja, com o mundo da especulação, sendo, assim, importante para a prática crucial da gestão do pensamento estratégico em geral (ALIGICA, 2005).

Diante disso, realça-se que a estratégia de cenários vem tomando lugar de extrema relevância e importância entre as ferramentas de suporte e melhora ao processo de tomada de decisão nas organizações (GOODWIN; WRIGHT, 2001; WRIGHT; GOODWIN, 2009), e um exemplo disso é que, nas últimas décadas, a literatura acadêmica sobre cenários registrou crescimento considerável nas publicações em revistas internacionais (AMER; DAIM; JETTER, 2013) e nacionais (WEISS et al., 2017). Entende-se e compreende-se que a utilização desta estratégia permite ao gestor, agir com mais segurança e melhor conhecimento 
da incerteza presente no futuro do cenário organizacional, garantindo, no processo decisório, que as decisões tomadas sejam com mais qualidade, criatividade, segurança e, consequentemente, velocidade (MORITZ; PEREIRA, 2005).

Em suma, cenários prospectivos definem recursos e estabelecem estratégias competitivas (SAURIN; RATCLIFFE, 2011), para ambientes turbulentos (GRANT, 2003) e incertos (MAGGS; CHELIN, 2013), e os gestores têm por desígnio, quando projetam analisar cenários dos negócios (GHEMAWAT, 2007), utilizá-los de maneira basilar (OLIVEIRA; FORTE, 2011) para escolhas de recursos (BARNEY, 1991), estratégias competitivas (PORTER, 1980) e capacidades empresariais (GHEMAWAT, 2007).

\subsection{ESTRATÉGIAS}

As capacidades e recursos, como estratégia, sendo elas, tangíveis ou intangíveis, direcionam a organização à obtenção da vantagem competitiva sustentável (CARDOSO; KATO, 2015), impactando consequentemente em seu desempenho (CARVALHO; KAYO; MARTIN, 2010). Os autores Carvalho, Kayo e Martin (2010) verificaram que a tangibilidade dos recursos contribui, de forma expressiva, para a persistência do desempenho superior das empresas de diversos setores da economia.

Martins et al. (2013) analisaram as estratégias e a alocação dos recursos nos programas de pós-graduação stricto sensu. Concluíram que, os programas com qualidade de excelência na avaliação da CAPES apresentaram estratégias deliberadas ao longo dos anos, tendo como foco a melhoria de seus desempenhos no sistema de avaliação da CAPES e também que foi utilizado o sistema de avaliação da CAPES como o direcionador estratégico.

Diante da rapidez das mudanças, a adoção de posturas estratégicas como forma de sustentar a competitividade tem sido uma contingência imposta pelo ambiente interno e externo (SANTOS; CÂNDIDO, 2013). É importante ressalvar que a Matriz SWOT busca consolidar aspectos que possam ser importantes para o negócio (OLIVEIRA; FORTE, 2014), agrupando os pontos fortes e fracos do ambiente interno, bem como as oportunidades e ameaças do ambiente externo (GONÇALVES, 2011). Diante do exposto, a organização pode escolher entre as seguintes posturas estratégicas: sobrevivência, manutenção, crescimento e desenvolvimento que são oriundas da Análise SWOT (SOUSA; FORTE; OLIVEIRA, 2012).

É importante salientar que o objetivo da SWOT é definir estratégias para manter pontos fortes, minimizar a intensidade de pontos fracos, aproveitando oportunidades e 
protegendo-se de possíveis ameaças. Diante da ênfase de pontos fortes ou fracos e de oportunidades e ameaças, pode-se formular, implementar e adotar estratégias que busquem a sobrevivência, manutenção, crescimento ou desenvolvimento da empresa (AZEVEDO; COSTA, 2010).

Nesse contexto, constatam-se densas variações ocorridas no sistema de ensino superior brasileiro desde o início da década de 1990, exigindo, por parte das IESs, posturas estratégicas que estejam cada vez mais integradas com o ambiente (AMARANTE; CRUBELLATE; MEYER JUNIOR, 2017). A IES, como organização, admite posturas estratégicas com o objetivo de orientar a afirmação de todas as suas iniciativas e políticas, necessárias para a instituição cumprir a missão a que se apoiou (MORITZ, 2012).

Isto posto, as referidas posturas serão colocadas em ênfase para se verificar a postura estratégica dos programas de pós-graduação stricto sensu e, a posteriori, observar a existência de relação entre tais posturas e suas respectivas estratégias competitivas e os cenários prospectados neste estudo.

\subsection{PÓS-GRADUAÇÃO NO BRASIL ÁREA DE ADMINISTRAÇÃO, CIÊNCIAS CONTÁBEIS E TURISMO}

No Brasil, o processo de avaliação da pós-graduação stricto sensu é conduzido pela Coordenação de Aperfeiçoamento de Pessoal de Nível Superior - CAPES (PATRUS; SHIGAKI; DANTAS, 2018), sendo esta vinculada ao Ministério da Educação - MEC (CAPES, 2019; MACCARI; RICCIO; MARTINS, 2013). Ressalta-se que, além da CAPES conduzir todo o sistema de avaliação de cursos de pós-graduação stricto sensu, ela também avalia as propostas de cursos novos de pós-graduação no Brasil (CAPES, 2018). A área de administração encontra-se presente na pós-graduação stricto sensu no Brasil desde os seus primeiros passos. Os primeiros programas de pós-graduação stricto sensu surgiram no Rio de Janeiro, São Paulo, Minas Gerais, Rio Grande do Sul e Paraíba. Destes, destaca-se o programa de mestrado em Administração da Fundação Getúlio Vargas (FGV) do Rio de Janeiro que foi o primeiro a surgir (VIEIRA; VIANA; ZABALZA, 2016).

Nos anos de 1970, três cursos de doutorado foram criados: dois no estado de São Paulo e um no Rio de Janeiro (CIRANI; SILVA; CAMPANARIO, 2012). Na década de 80, apareceram outros programas de mestrado e doutorado em administração em diversos outros Estados da Federação (BERTERO; CALDAS; WOOD JR, 1999). Nos últimos anos, a pós- 
graduação stricto sensu em Administração alcançou grande crescimento, e esta expansão pode ser em decorrência não somente pelos estímulos orçamentários do governo propostos a essa modalidade de ensino, mas, especialmente, pelo aumento da demanda da sociedade por maior nível de escolarização, que se tornou uma exigência fundamental para o ingresso no mercado de trabalho (VIEIRA; VIANA; ZABALZA, 2016).

Já a área de Ciências Contábeis é contemporânea, foi na Faculdade de Ciências Econômicas e Administrativas (FEA-USP) também que, em 1970, instalou-se o primeiro programa de pós-graduação stricto sensu em Ciências Contábeis no Brasil. Em 1978, a FEAUSP inseriu o primeiro doutorado em Contabilidade, realçando seu pioneirismo no ensino superior contábil no stricto sensu no Brasil (FRANCO; PAIVA; HELMOND, 2015). Diante do exposto, esboça-se que a pós-graduação stricto sensu em Ciências Contábeis vem se alargando de maneira expressiva, a partir de 1998, quando havia apenas três programas de mestrado e um de doutorado. Atualmente, existem, no Brasil, mais de 20 programas de pósgraduação stricto sensu em ciências contábeis, com cursos de doutorados, de mestrados profissionais e de mestrados acadêmicos autorizados pela CAPES (MIRANDA; CASA NOVA; CORNACCHIONE JR, 2013). Salienta-se, ainda, o crescimento de doutorados em Ciências Contábeis, pois passou de um curso em 2006 para 12 em 2016 (CAPES, 2016).

Em 1991, o primeiro Programa de Pós-Graduação Stricto Sensu em Turismo da Escola de Comunicações e Artes - ECA da Universidade de São Paulo (USP) foi aprovado para mestrado e doutorado não somente no Brasil, mas também na América Latina, iniciando sua expansão em meados de 1998 (SANTOS; REJOWSKI, 2013). Na área de Turismo não havia doutorados em 2006 e, atualmente, são quatro cursos (CAPES, 2016, p. 2). Em suma, A área de Administração Pública, Administração de Empresas, Ciências Contábeis e Turismo agrupa 184 Programas de Pós-Graduação, 62 Doutorados, 107 Mestrados Acadêmicos e 75 Mestrados Profissionais. São 11 Programas de Pós-Graduação em Administração Pública, 135 Administração de Empresas, 27 Ciências Contábeis e 11 em Turismo (CAPES, 2016).

\section{PROCEDIMENTOS METODOLÓGICOS}

Com o objetivo de identificar as estratégias com "extrema utilização" dos Programas de Stricto Sensu das Instituições de Ensino Superior do Brasil da área de Administração Pública e de Empresas, Ciências Contábeis e Turismo frente aos cenários prospectados para o período de 2019 a 2030. Este estudo prospectou os pareceres de gestores dos Programas de 
Stricto Sensu, embasada pela metodologia sugerida por Blanning e Reinig (1998). Entende-se, com isso, que, essa investigação é o tipo exploratória e descritiva. $\mathrm{O}$ universo deste estudo foram os Programas Stricto Sensu das Instituições de Ensino Superior Públicas e Privadas do Brasil da Área de Administração Pública e de Empresas, Ciências Contábeis e Turismo. Em razão de este universo contribuir para o aperfeiçoamento de cursos de doutorado e mestrado por meio do trabalho científico (MACCARI et al., 2009); e se verificar que a pós-graduação stricto sensu é um sucesso em termos de nações emergente, justifica-se, assim, focar este estudo neste universo de pesquisa.

Evidenciam-se que os Programas Stricto Sensu das Instituições de Ensino Superior Públicas e Privadas do Brasil da Área de Administração Pública e de Empresas, Ciências Contábeis e Turismo existentes e associados a Associação Nacional de Pós-Graduação e Pesquisa em Administração (ANPAD) fizeram parte do universo de estudo desta pesquisa. Versa-se que a amostra dos Programas Stricto Sensu das Instituições de Ensino Superior Públicas e Privadas do Brasil da Área de Administração para se realizar este estudo foi feita por acessibilidade. A amostra foi composta pelos Programas Associados a ANPAD, composto por 126 programas. A primeira etapa de coleta de dados da referida pesquisa, foram as entrevistas com cinco peritos (Quadro 1), todos doutores e vinculados a programas de pósgraduação stricto sensu da área de Administração Pública e de Empresas, Ciências Contábeis e Turismo.

Quadro 1 Peritos entrevistados

\begin{tabular}{|c|c|c|}
\hline Peritos & Organização & Curso/Programa \\
\hline Entrevistado 1 & IES privada & Programa de Mestrado Profissional em Administração \\
\hline Entrevistado 2 & IES privada & $\begin{array}{c}\text { Doutorado e Mestrado em Administração } \\
\text { Programa de Mestrado }\end{array}$ \\
\hline Entrevistado 3 & IES privada & Programa de Mestrado Acadêmico em Administração \\
\hline Entrevistado 4 & IES pública & Mestrado Profissional em Empreendedorismo \\
\hline Entrevistado 5 & IES pública & Programa de Pós-Graduação em Administração \\
\hline
\end{tabular}

Fonte: Dados da pesquisa.

Os mesmos foram selecionados mediante acessibilidade. Com estes cinco entrevistados iniciou-se a construção de uma lista de eventos, pois, estes peritos são sabedores de informações úteis, de observações e impressões importantes para esses eventos futuros (BLANNING; REINIG, 2002). Dando continuidade à construção dos eventos, uma listagem destes eventos foi enviada, por meio de perguntas, utilizando uma survey a 35 peritos, 
conseguindo uma devolutiva de 29 (Quadro 2) para que indicassem a probabilidade de ocorrência destes eventos e o quão favorável e pertinentes estes serão caso ocorra em uma linha graduada de zero a dez. Ressalva-se que os dados foram coletados mediante uma survey online, hospedada na plataforma Survey Monkey e distribuída por diversas mídias para os 35 peritos. A survey foi conduzida de forma que o respondente deliberadamente respondia ao questionário.

Quadro 2: Peritos

\begin{tabular}{|c|c|c|c|}
\hline Peritos (P) & Titulação & Organização & Função \\
\hline P1 & Doutor(a) & IES privada & Diretor(a) \\
\hline P2 & Doutor(a) & IES pública & Docente/Pesquisador(a) \\
\hline P3 & Doutor(a) & IES privada & Docente/Pesquisador(a) \\
\hline P4 & Doutor(a) & IES privada & Docente/Pesquisador(a) \\
\hline P5 & Doutor(a) & IES privada & Docente/Pesquisador(a) \\
\hline P6 & Doutor(a) & IES pública & Docente/Pesquisador(a) \\
\hline P7 & Doutor(a) & IES privada & Docente/Pesquisador(a) \\
\hline P8 & Doutor(a) & IES privada & Docente/Pesquisador(a) \\
\hline P9 & Doutor(a) & IES pública & Docente/Pesquisador(a) \\
\hline P10 & Doutor(a) & IES pública & Docente/Pesquisador(a) \\
\hline P11 & Doutor(a) & IES pública & Docente/Pesquisador(a) \\
\hline P12 & Doutor(a) & IES privada & Diretor(a) \\
\hline P13 & Doutor(a) & IES privada & Docente/Pesquisador(a) \\
\hline P14 & Doutor(a) & IES privada & Diretor(a) \\
\hline P15 & Doutor(a) & IES privada & Docente/Pesquisador(a) \\
\hline P16 & Doutor(a) & IES pública & Docente/Pesquisador(a) \\
\hline P17 & Doutor(a) & IES pública & Docente/Pesquisador(a) \\
\hline P18 & Doutor(a) & IES pública & Docente/Pesquisador(a) \\
\hline P19 & Doutor(a) & IES pública & Docente/Pesquisador(a) \\
\hline P20 & Doutor(a) & IES pública & Docente/Pesquisador(a) \\
\hline P21 & Doutor(a) & IES privada & Docente/Pesquisador(a) \\
\hline P22 & Doutor(a) & IES privada & Docente/Pesquisador(a) \\
\hline P23 & Doutor(a) & IES privada & Docente/Pesquisador(a) \\
\hline P24 & Doutor(a) & IES privada & Diretor(a) \\
\hline P25 & Doutor(a) & IES privada & Diretor(a) \\
\hline P26 & Doutor(a) & IES pública & Docente/Pesquisador(a) \\
\hline P27 & Doutor(a) & IES privada & Docente/Pesquisador(a) \\
\hline P28 & Doutor(a) & IES privada & Docente/Pesquisador(a) \\
\hline P29 & Doutor(a) & IES privada & Diretor(a) \\
\hline
\end{tabular}

Fonte: Dados da pesquisa

Aplicou-se o questionário de acordo com o método de sugerido por Blanning e Reinig (1998). Salienta-se que, no que tange a estrutura do questionário, foi embasado e norteado nos conceitos de pertinência (MARCIAL; GRUMBACH, 2002) e de favorabilidade e probabilidade (BLANNING; REINIG, 1998). Com isso, em relação à pertinência, os peritos 
aferiram em uma escala tipo Likert de zero a cinco, em que (zero = sem influência; um = muito pouca influência; dois = pouca influência; três = razoável influência; quatro = forte influência; e cinco = extrema influência). De maneira geral, os peritos focaram sobre a pertinência da ocorrência ou não de algum evento na construção dos cenários, sendo o critério pertinência (importância) livre da possibilidade de ocorrência deste evento ou não (MARCIAL; GRUMBACH, 2002).

No que se refere à favorabilidade, que versa sobre o quanto o evento é aderente para a construção dos cenários. Com isso, para esse critério, foi utilizada a escala (zero a 100\%, com intervalos de $10 \%$ em 10\%). Para o discernimento da perspectiva de ocorrência das variáveis na construção dos cenários, também foi utilizada a escala de zero a $100 \%$, com intervalos de 10\% em 10\% (BLANNING; REINIG, 1998). Logo em seguida, foi realizada a construção de uma matriz de eventos, colocando no eixo horizontal as expectativas de ocorrência destes eventos (P) e, no eixo vertical, o quanto cada evento é apto ou contrário (F) para as instituições que estão sendo desenvolvidas as análises (BLANNING; REINIG, 1998).

Quadro 3: Eventos

\section{Eventos}

O programa procura manter as notas de excelência da Coordenação de Aperfeiçoamento de Pessoal de Nível Superior (CAPES)

O programa incentiva a participação dos docentes em grupos de pesquisa, convênios e intercâmbios com universidades e centros de pesquisa do exterior

O programa incentiva a publicação em periódicos internacionais como fator de impacto

Corpo docente de alta performance na produção acadêmica e relevância internacional é recurso estratégico

Recursos estratégicos criam vantagem competitiva sustentável no programa de pós-graduação stricto sensu

Grupos e projetos de pesquisa são formados para fortalecer a publicação científica, bem como parcerias internacionais

Recursos estratégicos são essenciais para qualidade no programa de pós-graduação stricto sensu

A presença de renomados professores internacionais em eventos, palestras, cursos, e

"summercourses", incentivam a internacionalização do programa

O programa incentiva, com recursos, a participação de docentes e discente em eventos internacionais

Recursos estratégicos impactam na formação de pesquisadores e contribuem no desenvolvimento de suas atividades

Recursos estratégicos são preponderantes para incentivar a internacionalização do Programa de PósGraduação Stricto Sensu

O programa integra docentes de outras IESs para desenvolver pesquisas conjuntas

O processo seletivo estimula participação de candidatos, com base no mérito e desempenho acadêmico

O programa de Pós-Graduação Stricto Sensu influencia na atuação de egressos em programas de stricto sensu de diferentes regiões

Fonte: Dados da pesquisa 
Ressalta-se que o processo de filtragem dos eventos foi feito por meio das seguintes ações: (i) cinco especialistas indicaram admissíveis e possíveis eventos; (ii) uma survey a 29 peritos; e (iii) busca na literatura científica destes eventos (MACCARI et al., 2009; MACCARI; LIMA; RICCIO, 2009; MACCARI; RICCIO; MARTINS, 2013; MORITZ et al., 2013; MORITZ; NUNER; PEREIRA, 2008; SOUSA; FORTE; OLIVEIRA, 2012). Foi feito uma consolidação destes eventos, evitando assim duplicidade e ou redundância destes, surgindo com isso os eventos evidenciados no Quadro 3.

Quadro 4: Posturas e estratégias

\begin{tabular}{|c|l|}
\hline Posturas & \multicolumn{1}{c|}{ Estratégias } \\
\hline & $\begin{array}{l}\text { - Reduzir custos (pessoal, despesas administrativas, enxugamento da estrutura } \\
\text { organizacional) }\end{array}$ \\
& - Diminuir o número de cursos de stricto sensu \\
- Inserir novos sócios nos negócios das IESs \\
- Perder o controle acionário/patrimonial da IES, impactando no programa stricto sensu \\
- Negociar com grupos de interesses institucionais \\
- Mudar objetivos, atividades ou domínios \\
- Contestar regras e exigências \\
- Violar as fontes de pressão institucional
\end{tabular}




\begin{tabular}{|l|l|}
\hline Posturas & \multicolumn{1}{|c|}{ Estratégias } \\
\hline & $\begin{array}{l}\mid c \\
\text { - Abrir o capital por lançamento de ações (mercado primário de ações) da IES } \\
\text { - Incentivar e ou inserir o foco cultural, ecológica e social de relevância da IES } \\
\text { - Investir em negócios não relacionados com a IES (em outras empresas) } \\
\text { - Dominar públicos e processos institucionais } \\
\text { - Fomentar a reputação do programa stricto sensu, mediante a atuação do egresso do } \\
\text { programa na sociedade }\end{array}$ \\
& $\begin{array}{l}\text { - Alargar a exigência para produção científica por parte dos professores que podem ser } \\
\text { credenciados com o perfil acadêmico ou profissional, respeitando os limites impostos pelo } \\
\text { sistema }\end{array}$ \\
& $\begin{array}{l}\text { - Fazer com que o programa stricto sensu necessite atender às necessidades dos } \\
\text { stakeholders } \\
\text { - Criar um setor específico para a internacionalização } \\
\text { - Desenvolver doutorado acadêmico ou profissional internacional ou mestrado acadêmico } \\
\text { ou profissional internacional ou pós-doutorado } \\
\text { - Aperfeiçoar a internacionalização na formação do pessoal do ensino superior no Brasil } \\
\text { - Incluir Bolsas de doutorado sanduíche no exterior - Capes, e ou de pós-doutorado } \\
\text { - Consolidar relacionamentos interinstitucionais por meio de programas permanentes de } \\
\text { dupla titulação em nível de mestrado e doutorado } \\
\text { - Desenvolver programa institucional de créditos acadêmicos ofertados no exterior }\end{array}$ \\
\hline
\end{tabular}

Fonte: Dados da pesquisa.

Para se conseguir responder e alcançar a questão de pesquisa e o objetivo deste estudo, foi realizada uma outra survey. A survey foi administrada de maneira que o respondente deliberadamente respondia ao questionário. Ao todo, 41 respondentes formaram a amostra dos dados. Este estudo utilizou técnicas estatísticas, tais como estatística descritiva. Ao todo, 47 estratégias (Quadro 4) foram submetidas à avaliação dos respondentes, cada uma sendo avaliada em três cenários: pessimista, realista e otimista. As estratégias foram redigidas sob afirmações e avaliadas em uma escala likert de zero a cinco. Ressaltam-se que as citadas estratégias foram elencadas e organizadas por meio das suas respectivas posturas mediante uma revisão da literatura, utilizando estudos, sobretudo, de artigos publicados em revistas científicas (MACCARI et al., 2009; MACCARI; LIMA; RICCIO, 2009; MACCARI; RICCIO; MARTINS, 2013; MORITZ et al., 2013; MORITZ; NUNER; PEREIRA, 2008; SOUSA; FORTE; OLIVEIRA, 2012).

\section{ANÁLISE E DISCUSSÃO DOS RESULTADOS}

Esta seção traz em seu bojo a análise e discussão das estratégias com "extrema utilização" dos Programas de Stricto Sensu das IESs do Brasil da área de Administração Pública e de Empresas, Ciências Contábeis e Turismo. 


\subsection{ESTRATÉGIAS COM EXTREMA UTILIZAÇÃO NO CENÁRIO OTIMISTA}

Antes de adentrar às próximas análises nas Tabelas 1, 2 e 3, é importante ressalvar que a escala utilizada tem seis pontos delineados em sequências de caracteres. Uma estratégia que não é cogitada para ser utilizada em algum cenário, recebe a codificação 0 na escala. Os demais pontos vão, de forma crescente, apontando intensidade e importância na utilização de determinada estratégia. Como cada item foi avaliado separadamente em cada cenário, o mesmo respondente poderia marcar 0 em um cenário e, para o mesmo item, marcar seis em outro cenário. Portanto, cada cenário possui suas próprias variáveis e que devem ser analisadas individualmente.

As taxas de frequências em cada ponto da escala estão sendo apresentadas na Tabela 1, sendo escolhidas as 10 variáveis com maior porcentagem no ponto máximo da escala, referente a "extrema utilização". Na Tabela 1, o fomento a qualidade das teses e das dissertações foi uma estratégia que recebeu o maior número de pontos máximos da escala, revelando que os respondentes, em um cenário otimista, julgam que é importante implementar esta estratégia.

Importante ressaltar que, ao fomentar a qualidade das dissertações e ou teses dos programas stricto sensu ora analisados, estes, no cenário otimista, transparece a seriedade, envergadura e robustez das linhas de pesquisa que alicerçam os respectivos programas, impactando diretamente, a posteriori, em publicações que serão divulgadas em meios de comunicação (eventos e ou revistas científicas de com alto fator de impacto), contribuindo para que estes programas evoluam na vitrine do mercado acadêmico nacional (SOUSA; FORTE; OLIVEIRA, 2012) e quiçá internacional.

Aqui é importante salientar que a produção científica internacional aumentou e melhorou nos últimos anos. Tal constatação e resultado é creditada em razão das transformações de critérios de valorização da produção acadêmica da área em análise a partir do Triênio 2007-2009 e que foi anunciada em 2005. Com isso, deixou-se de valorar a produção em congressos para prestigiar apenas artigos em periódicos científicos, sobretudo de bom fator de impacto (CAPES, 2016). Reitera-se, assim, a importância de potencializar e estimar a produção científica nos programas de pós-graduação, como estratégia competitiva (HEINZEN; MARINHO, 2018), em diferentes cenários alternativos (GOODWIN; WRIGHT, 2001). 
Não obstante, as maiores médias convergem com os itens de maior frequência na escala máxima. As outras estratégias que se destacaram nesta seção da pesquisa foram: (a) Fortalecer política de cooperação interinstitucional; (b) Inserir programa de bolsas estudante convênio de pós-graduação - Capes; (c) Desenvolver e capacitar o corpo docente; (d) Incluir bolsas de doutorado sanduíche no exterior - Capes, e ou de pós-doutorado; (e) Atrair para o programa professor visitante do exterior - Capes; (f) Criar métricas que visem ampliar a qualidade e desempenho do stricto sensu; (g) Ter maior profissionalismo do programa stricto sensu; (h) Criar um setor específico para a internacionalização; e (i) Fazer parcerias com outras IESs de outras regiões/países, criando Minters e Dinters.

Quando é enfatizada a estratégia "Desenvolver e capacitar o corpo docente", esta também está atrelada a um dos objetivos principais de um curso de pós-graduação stricto sensu que é formar mestres e doutores (CAPES, 2018), com isso, tal fato incorre na formação dos docentes / pesquisador, dando a eles habilidades e competências (MORITZ et al., 2013) capazes de lhes transformar em profissionais com maior conhecimento científico em suas respectivas área do saber, contribuindo para uma independência científica e intelectual, colaborando para o progresso científico, tecnológico, econômico e social do Brasil (CAPES, 2018).

No que se refere à estratégia "Criar um setor específico para a internacionalização", é importante que os programas de stricto sensu invistam em recursos na internacionalização dos seus cursos de pós-graduação, na interação institucional, recompensando aqueles que tiverem fluxo in e out bound de discentes e docentes / pesquisadores, projetos de pesquisa científica em conjuntos, discentes com dupla titulação, disciplinas conjuntas, oferta de cursos em inglês e outras línguas, dentre outras iniciativas e, sobretudo, resultados estruturados e expressos em resultados avaliativos e impactos, seja para o desenvolvimento de políticas institucionais, seja da perspectiva científica, econômica e cultural ao país (CAPES, 2018).

Fazendo uma análise, no que tange a hierarquia das estratégias elencadas na Tabela 1, observa-se que o fortalecimento da política de cooperação interinstitucional (MORITZ et al., 2013) fará com que os programas possam inserir, em suas políticas, programa de bolsas de estudos (MORITZ et al., 2013). Além disso, proporcionará a possibilidade de desenvolver o corpo docente, mediante parcerias com professores de IESs de outras regiões (CIRANI; SILVA; CAMPANARIO, 2012) e ou países, atraindo pesquisadores visitantes do exterior em decorrência destas parcerias, e isso, por sua vez, impactará na criação de métricas que visem 
ampliar a qualidade e o desempenho dos programas stricto sensu. Tal fato otimizará o maior profissionalismo destes programas, contribuindo para ganhos de valor acadêmico, o que favorecerá sua futura inserção no âmbito internacional, mediante estratégias de internacionalização (MORITZ et al., 2013), ajudando, com isso, aos programas stricto sensu evoluírem e fazendo com que surjam, por exemplo, novos programas com outras instituições de outras regiões/países, criando, com isso, acessibilidade para novos mestrandos e ou doutorando (MACCARI; LIMA; RICCIO, 2009), por meio de Minters e Dinters.

Tabela 1 Cenário otimista: as 10 maiores estratégias com extrema utilização

\begin{tabular}{|c|c|c|c|c|c|c|c|}
\hline Estratégias & Posturas & $\begin{array}{c}\text { Sem } \\
\text { utilização }\end{array}$ & $\begin{array}{c}\text { Muito } \\
\text { pouca } \\
\text { utilização } \\
\end{array}$ & $\begin{array}{c}\text { Pouca } \\
\text { utilização }\end{array}$ & $\begin{array}{l}\text { Razoável } \\
\text { utilização }\end{array}$ & $\begin{array}{c}\text { Forte } \\
\text { utilização }\end{array}$ & $\begin{array}{c}\text { Extrema } \\
\text { utilização }\end{array}$ \\
\hline $\begin{array}{l}\text { Fomentar a qualidade das teses } \\
\text { e das dissertações }\end{array}$ & Manutenção & $0,00 \%$ & $2,44 \%$ & $2,44 \%$ & $9,76 \%$ & $43,90 \%$ & $41,46 \%$ \\
\hline $\begin{array}{l}\text { Fortalecer política } \mathrm{de} \\
\text { cooperação interinstitucional }\end{array}$ & Manutenção & $0,00 \%$ & $0,00 \%$ & $2,44 \%$ & $9,76 \%$ & $46,34 \%$ & $41,46 \%$ \\
\hline $\begin{array}{l}\text { Inserir programa de bolsas } \\
\text { estudante - convênio de pós- } \\
\text { graduação - Capes }\end{array}$ & Manutenção & $2,44 \%$ & $2,44 \%$ & $2,44 \%$ & $21,95 \%$ & $29,27 \%$ & $41,46 \%$ \\
\hline $\begin{array}{lll}\begin{array}{l}\text { Desenvolver e capacitar } \\
\text { corpo docente }\end{array} & \\
\end{array}$ & Manutenção & $2,44 \%$ & $2,44 \%$ & $0,00 \%$ & $21,95 \%$ & $34,15 \%$ & $39,02 \%$ \\
\hline $\begin{array}{l}\text { Incluir bolsas de doutorado } \\
\text { sanduíche no exterior - Capes, } \\
\text { e/ou de pós-doutorado }\end{array}$ & Desenvolvimento & $4,88 \%$ & $0,00 \%$ & $4,88 \%$ & $19,51 \%$ & $34,15 \%$ & $36,59 \%$ \\
\hline $\begin{array}{l}\text { Atrair para o programa } \\
\text { professor visitante do exterior } \\
\text { - Capes }\end{array}$ & Manutenção & $2,44 \%$ & $0,00 \%$ & $4,88 \%$ & $4,88 \%$ & $56,10 \%$ & $31,71 \%$ \\
\hline $\begin{array}{l}\text { Criar métricas que visem } \\
\text { ampliar a qualidade e } \\
\text { desempenho do stricto sensu }\end{array}$ & Manutenção & $0,00 \%$ & $0,00 \%$ & $2,44 \%$ & $17,07 \%$ & $48,78 \%$ & $31,71 \%$ \\
\hline $\begin{array}{l}\text { Ter maior profissionalismo do } \\
\text { programa stricto sensu }\end{array}$ & Manutenção & $0,00 \%$ & $0,00 \%$ & $2,44 \%$ & $12,20 \%$ & $53,66 \%$ & $31,71 \%$ \\
\hline $\begin{array}{l}\text { Criar um setor específico para } \\
\text { a internacionalização }\end{array}$ & Desenvolvimento & $0,00 \%$ & $0,00 \%$ & $0,00 \%$ & $21,95 \%$ & $46,34 \%$ & $31,71 \%$ \\
\hline $\begin{array}{l}\text { Fazer parcerias com outras } \\
\text { IESs de outras regiões/países, } \\
\text { criando Minters e Dinters }\end{array}$ & Manutenção & $2,44 \%$ & 2,44 & $0,00 \%$ & $12,20 \%$ & $53,66 \%$ & $29,27 \%$ \\
\hline
\end{tabular}

Fonte: Dados da pesquisa.

Com foco na internacionalização do programa, mais propriamente, ao enfatizar a criação de um setor específico para a internacionalização (Tabela 1), no entendimento da Capes (2016), a internacionalização de um programa de pós-graduação correspondente na sua efetiva contribuição para a sociedade, pois fomentará seu conhecimento científico atuando fora do Brasil. Isto posto, constata-se que a preparação e formação de novos pesquisadores e ou profissionais (discentes e egressos) na competição pelas melhores posições de trabalho no mercado nacional e internacional, pode ser um exemplo de mensuração do grau da 
internacionalização de um programa de pós-graduação stricto sensu do Brasil (CAPES, 2016).

\subsection{ESTRATÉGIAS COM EXTREMA UTILIZAÇÃO NO CENÁRIO REALISTA}

$\mathrm{Na}$ Tabela 2, percebe-se que há um maior equilíbrio entre os pontos da escala. Enquanto no cenário otimista, há vários pontos zerados, no cenário realista os itens foram julgados de forma diferente por alguns respondentes, justificando o aumento na taxa de variabilidade.

Tabela 2 Cenário realista: as 10 maiores estratégias com extrema utilização

\begin{tabular}{|c|c|c|c|c|c|c|c|}
\hline Estratégias & Postura & $\begin{array}{c}\text { Sem } \\
\text { utilização }\end{array}$ & $\begin{array}{c}\text { Muito } \\
\text { pouca } \\
\text { utilização }\end{array}$ & $\begin{array}{c}\text { Pouca } \\
\text { utilização }\end{array}$ & $\begin{array}{l}\text { Razoável } \\
\text { utilização }\end{array}$ & $\begin{array}{l}\text { Forte } \\
\text { utilização }\end{array}$ & $\begin{array}{c}\text { Extrema } \\
\text { utilização }\end{array}$ \\
\hline Desenvolver e capacitar o corpo docente & Manutenção & $2,44 \%$ & $2,44 \%$ & $17,07 \%$ & $29,27 \%$ & $21,95 \%$ & $26,83 \%$ \\
\hline $\begin{array}{l}\text { Inserir programa de bolsas estudante }- \\
\text { convênio de pós-graduação - Capes }\end{array}$ & Manutenção & $4,88 \%$ & $0,00 \%$ & $17,07 \%$ & $26,83 \%$ & $26,83 \%$ & $24,39 \%$ \\
\hline $\begin{array}{l}\text { Fomentar a qualidade das teses e das } \\
\text { dissertações }\end{array}$ & Manutenção & $0,00 \%$ & $0,00 \%$ & $12,20 \%$ & $29,27 \%$ & $36,59 \%$ & $21,95 \%$ \\
\hline $\begin{array}{l}\text { Ter maior profissionalismo do programa } \\
\text { stricto sensu }\end{array}$ & Manutenção & $2,44 \%$ & $4,88 \%$ & $4,88 \%$ & $26,83 \%$ & $39,02 \%$ & $21,95 \%$ \\
\hline $\begin{array}{llll}\begin{array}{l}\text { Fortalecer política } \\
\text { interinstitucional }\end{array} & \text { de cooperação } \\
\end{array}$ & Manutenção & $0,00 \%$ & $7,32 \%$ & $4,88 \%$ & $21,95 \%$ & $46,34 \%$ & $19,51 \%$ \\
\hline $\begin{array}{l}\text { Fazer parcerias com outras IESs de outras } \\
\text { regiões/países, criando Minters e Dinters }\end{array}$ & Manutenção & $7,32 \%$ & $2,44 \%$ & $7,32 \%$ & $39,02 \%$ & $29,27 \%$ & $14,63 \%$ \\
\hline Planejar programas estratégicos específicos & Manutenção & $2,44 \%$ & $2,44 \%$ & $14,63 \%$ & $31,71 \%$ & $34,15 \%$ & $14,63 \%$ \\
\hline $\begin{array}{l}\text { Formar, de maneira adequada, o aluno no seu } \\
\text { desenvolvimento profissional }\end{array}$ & Manutenção & $0,00 \%$ & $0,00 \%$ & $12,20 \%$ & $29,27 \%$ & $43,90 \%$ & $14,63 \%$ \\
\hline $\begin{array}{l}\text { Atrair para o programa professor visitante do } \\
\text { exterior - Capes }\end{array}$ & Manutenção & $4,88 \%$ & $2,44 \%$ & $14,63 \%$ & $19,51 \%$ & $43,90 \%$ & $14,63 \%$ \\
\hline $\begin{array}{l}\text { Fomentar a reputação do programa stricto } \\
\text { sensu, mediante a atuação do egresso do } \\
\text { programa na sociedade }\end{array}$ & Desenvolvimento & $2,44 \%$ & $4,88 \%$ & $21,95 \%$ & $19,51 \%$ & $36,59 \%$ & $14,63 \%$ \\
\hline
\end{tabular}

Fonte: Dados da pesquisa.

Neste diapasão, predomina, nessa seção, a ênfase na estratégia "Desenvolver e capacitar o corpo docente", para o cenário realista. Tal estratégia pode ser colocada como preponderante para o alcance dos objetivos e metas dos programas de stricto sensu ora em investigação, no que tange a: (i) otimizar a qualidade das teses e das dissertações; (ii) influenciar no maior profissionalismo do programa stricto sensu; (iii) fortalecer política de cooperação interinstitucional, sobretudo para as regiões menos favorecidas; (iv) fomentar parcerias com outras instituições de outras regiões/países, possibilitando a criação de programas, tais como Minters e Dinters, acolhendo assim a cooperação entre IESs; (v) docentes com maior capacitação, serão úteis para planejar, implementar e adotar políticas 
estratégicas específicas, alargando, com isso, o potencial acadêmico dos programas stricto sensu no Brasil; (vi) ajudar a formar de maneira adequada e satisfatória o discente no seu desenvolvimento profissional; (vii) extrair parcerias com professores do exterior; e (viii) ajudar indiretamente na promoção da reputação do programa stricto sensu, por meio da atuação do egresso do programa na sociedade.

Como é possível observar, a estratégia mais extremamente utilizada no cenário realista "Desenvolver e capacitar o corpo docente" alicerça oito das nove estratégias evidenciadas na Tabela 1, vislumbrando, assim, sua importância para o aperfeiçoamento, crescimento, difusão e socialização do conhecimento científico das áreas de Administração Pública e de Empresas, Ciências Contábeis e Turismo à luz dos programas stricto sensu investigados nesta pesquisa. Tal resultado é salutar, pois mostra, como dito antes, a relevância dos docentes/pesquisadores (MORITZ et al., 2013), para o embasamento e a evolução do saber científico, impactando diretamente na evolução, envergadura e respeito aos programas stricto sensu ora analisados no panorama nacional e internacional.

No que tange ao destaque dos programas de pós-graduação no âmbito internacional, evidencia-se que esta característica é uma forma de se avaliar a inserção internacional (internacionalização) que o programa tem fora do Brasil, por meio da atuação dos seus pesquisadores (docentes, discentes e egressos), mediante seus grupos de pesquisa. Nesse âmbito, a circulação que se mensura é nos dois sentidos, isto é, pesquisadores do Brasil para o exterior e os estrangeiros vindo para o Brasil (CAPES, 2016). Outra forma de calcular o respeito e a envergadura que os programas de pós-graduação têm no âmbito internacional se dá por meio do prestígio dos seus pesquisadores, mediante a atuação destes, tais como diretores ou presidentes de sociedade científica internacional, ou como editores de revistas científicas proeminentes para a comunidade internacional da área de administração pública e de empresas, ciências contábeis e turismo (CAPES, 2016).

\subsection{ESTRATÉGIAS COM EXTREMA UTILIZAÇÃO NO CENÁRIO PESSIMISTA}

A Tabela 3 contempla o cenário pessimista com as suas 10 maiores estratégias com extrema utilização. No cenário pessimista, é notória a hegemonia da variável "Reduzir Custos (pessoal, despesas administrativas, enxugamento da estrutura organizacional)", como estratégia viável neste cenário. Esta resposta vai ao encontro da mais normal estratégia dos gestores em possíveis cenários incertos (MAGGS; CHELIN, 2013), que é justamente enxugar 
gastos, isto é, mitigar custos. As outras nove estratégias que ficam enfatizadas nesta seção foram: (a) desenvolver e capacitar o corpo docente; (b) aperfeiçoar as linhas de pesquisa do programa stricto sensu; (c) fomentar a qualidade das teses e das dissertações; (d) ter maior profissionalismo do programa stricto sensu; (e) alargar a exigência para produção científica por parte dos professores que podem ser credenciados com o perfil acadêmico ou profissional, respeitando os limites impostos pelo sistema; (f) investir em Marketing no programa stricto sensu; (g) fortalecer política de cooperação interinstitucional; (h) formar, de maneira adequada, o aluno no seu desenvolvimento profissional; e (i) inserir Programa de bolsas estudante - convênio de pós-graduação - CAPES.

Tabela 3 Cenário pessimista: as 10 maiores estratégias com extrema utilização

\begin{tabular}{|c|c|c|c|c|c|c|c|}
\hline Estratégias & Posturas & $\begin{array}{c}\text { Sem } \\
\text { utilização }\end{array}$ & $\begin{array}{c}\text { Muito } \\
\text { pouca } \\
\text { utilização }\end{array}$ & $\begin{array}{c}\text { Pouca } \\
\text { utilização }\end{array}$ & $\begin{array}{l}\text { Razoável } \\
\text { utilização }\end{array}$ & $\begin{array}{c}\text { Forte } \\
\text { utilização }\end{array}$ & $\begin{array}{c}\text { Extrema } \\
\text { utilização }\end{array}$ \\
\hline $\begin{array}{l}\text { Reduzir custos (pessoal, despesas } \\
\text { administrativas, enxugamento da } \\
\text { estrutura organizacional) }\end{array}$ & Sobrevivência & $12,20 \%$ & $12,20 \%$ & $2,44 \%$ & $14,63 \%$ & $24,39 \%$ & $34,15 \%$ \\
\hline $\begin{array}{l}\text { Desenvolver e capacitar o corpo } \\
\text { docente }\end{array}$ & Manutenção & $21,95 \%$ & $12,20 \%$ & $14,63 \%$ & $9,76 \%$ & $14,63 \%$ & $26,83 \%$ \\
\hline $\begin{array}{l}\text { Aperfeiçoar as linhas de pesquisa do } \\
\text { programa stricto sensu }\end{array}$ & Manutenção & $12,20 \%$ & $12,20 \%$ & $14,63 \%$ & $9,76 \%$ & $29,27 \%$ & $21,95 \%$ \\
\hline $\begin{array}{l}\text { Fomentar a qualidade das teses e } \\
\text { das dissertações }\end{array}$ & Manutenção & $9,76 \%$ & $14,63 \%$ & $19,51 \%$ & $12,20 \%$ & $21,95 \%$ & $21,95 \%$ \\
\hline $\begin{array}{l}\text { Ter maior profissionalismo do } \\
\text { programa stricto sensu }\end{array}$ & Manutenção & $9,76 \%$ & $9,76 \%$ & $17,07 \%$ & $17,07 \%$ & $24,39 \%$ & $21,95 \%$ \\
\hline $\begin{array}{l}\text { Alargar a exigência para produção } \\
\text { científica por parte dos professores } \\
\text { que podem ser credenciados com o } \\
\text { perfil acadêmico ou profissional, } \\
\text { respeitando os limites impostos pelo } \\
\text { sistema }\end{array}$ & Desenvolvimento & $9,76 \%$ & $9,76 \%$ & $12,20 \%$ & $24,39 \%$ & $21,95 \%$ & $21,95 \%$ \\
\hline $\begin{array}{l}\text { Investir em Marketing no programa } \\
\text { stricto sensu }\end{array}$ & Manutenção & $21,95 \%$ & $14,63 \%$ & $9,76 \%$ & $12,20 \%$ & $21,95 \%$ & $19,51 \%$ \\
\hline $\begin{array}{l}\text { Fortalecer política de cooperação } \\
\text { interinstitucional }\end{array}$ & Manutenção & $12,20 \%$ & $19,51 \%$ & $7,32 \%$ & $17,07 \%$ & $24,39 \%$ & $19,51 \%$ \\
\hline $\begin{array}{l}\text { Formar, de maneira adequada, o } \\
\text { aluno no seu desenvolvimento } \\
\text { profissional }\end{array}$ & Manutenção & $9,76 \%$ & $17,07 \%$ & $7,32 \%$ & $12,20 \%$ & $34,15 \%$ & $19,51 \%$ \\
\hline $\begin{array}{l}\text { Inserir Programa de } \text { bolsas } \\
\text { estudante }- \text { convênio de pós- } \\
\text { graduação - Capes }\end{array}$ & Manutenção & $21,95 \%$ & $9,76 \%$ & $9,76 \%$ & $19,51 \%$ & $19,51 \%$ & $19,51 \%$ \\
\hline
\end{tabular}

Fonte: Dados da pesquisa.

De certa forma, entende-se que, para o cenário pessimista, a redução de custos (MORITZ et al., 2013) é prioritária para os programas neste tipo de cenário, como também o aperfeiçoamento do corpo docente, mediante capacitações, influenciando, com isso, no maior desenvolvimento das linhas de pesquisa do programa stricto sensu, colaborando assim para a 
otimização da qualidade das teses e das dissertações, divulgadas nos respectivos programas, o que contribui para que tais programas robusteçam o profissionalismo de suas atividades, criando valor científico e, ao mesmo tempo, auxiliam, de maneira direta, para o alargamento da produção científica de qualidade dos docentes.

Percebe-se também que, o referido cenário, parece ser propício para se investir em marketing, fortalecer a política de cooperação interinstitucional dos programas das IESs, ajudando, com isso, na formação do aluno no seu desenvolvimento profissional, sobretudo em regiões menos favorecidas. Isto posto, as 10 estratégias mais extremamente utilizadas esboçadas aqui, são preponderantes para se conseguir sustentar e dar continuidade aos negócios (WILKINSON; KUPERS; MANGALAGIU, 2013) e ao conhecimento científico disseminado pelos programas stricto sensu, objetivo de estudo nesta pesquisa. Nesse contexto que nos foi apresentado, contempla-se, no cenário pessimista desta seção, que há uma maior disparidade de opiniões dos respondentes em relação as melhores estratégias a serem adotadas. Mesmo sendo as 10 estratégias de maior frequência no ponto máximo da escala, boa parte dos itens têm os demais pontos da escala bem representados.

Ao analisar os três cenários: otimista, realista e pessimista evidenciados nesta subseção este estudo pretende contribuir para entender e compreender que tipos de estratégia podem ser adotadas em cenários prospectados e desejados para os Programas Stricto Sensu do Brasil (MORITZ et al., 2013). E, consequentemente, harmonizar um futuro economicamente ativo e socialmente equitativo na área da educação superior (POLESI, 2006). E, quando se manifesta o social, atrela-se a este, além da própria educação e a economia, também a cultura e a tecnologia (CAPES, 2016), ajudando com isso a minimizar as diferenças regionais, no que concerne ao conhecimento científico, contribuindo diretamente para o desenvolvimento das regiões menos favorecidas, por meio da inserção de novos profissionais egressos dos programas de pós-graduação emergentes, maduros ou legitimados do Brasil.

\section{CONCLUSÃO}

O objetivo deste estudo foi identificar as estratégias com "extrema utilização" dos Programas de Stricto Sensu das Instituições de Ensino Superior do Brasil da área de Administração Pública e de Empresas, Ciências Contábeis e Turismo frente aos cenários prospectados para o período de 2019 a 2030. Metodologicamente utilizou-se o método de cenários sugerida por Blanning e Reinig. Em relação ao uso extremo das estratégias nos 
cenários otimista e realista, realça-se o item "fomentar a qualidade das teses e das dissertações", confirmando sua importância na média de sua utilização e seu forte uso nos cenários otimista e realista. É importante salientar que, ao enfatizar a estratégia da qualidade das teses e das dissertações, se enfocam também o corpo docente-discente, da produção científica, e da eficiência e eficácia dos programas de pós-graduação stricto sensu na formação de novos mestres e doutores.

Quanto ao cenário pessimista, vislumbra-se novamente a estratégia "reduzir custos (pessoal, despesas administrativas, enxugamento da estrutura organizacional)", reiterando assim sua relevância, como estratégia a ser adotada em cenários turbulentos e ou incertos, ajudando assim a transformar a instituição e sua respectiva pós-graduação stricto sensu em uma IES mais ágil, flexível, eficiente, competitiva, que criar valor ao lidar com cenários adversos. Com isso, é possível afirmar que a metodologia de cenários é preponderante para a gestão estratégica em ambientes turbulentos. Conclui-se mediante os resultados deste estudo que é viável e plausível que as organizações podem e devem optar por uma metodologia de cenário que melhor se adapte a sua realidade e fazer uso durante seu processo estratégico a fim de colaborar para o alinhamento, entre a formulação, implementação e adoção de estratégias competitivas. Tal ação também se aplica as IESs e seus respectivos programas de pós-graduação stricto sensu da área do conhecimento objeto de estudo.

De maneira geral, o que se espera dos programas de pós-graduação stricto sensu no Brasil para 2030 é que ela aja com uma consciência estratégica alargada e robusta, atentando às condições para performar a aprendizagem humana do futuro, por meio de uma atuação mais pujante e conjunta dos docentes(pesquisadores)/discentes/gestores/instituições contribuindo para o fomento da qualidade da pesquisa nos mestrados e doutorados, e, concomitantemente, colaborando diretamente na qualificação sólida de novos e diferentes egressos, impactando em uma maior inserção social, cooperação interinstitucional e crescimento da qualidade da produção científica do conhecimento da área em análise neste estudo.

Como limitação do estudo, enfatiza-se o longo período de espera para concluir a última etapa de coleta de dados, porém tal obstáculo não causou prejuízo no que concerne a responder e a alcançar a questão e o objetivo da pesquisa, respectivamente. Segue adiante algumas sugestões para estudos futuros, tais como: replicar o referido estudo, abrangendo, não somente a área de administração pública e de empresas, ciências contábeis e turismo, mas 
também, outros campos do saber. Contrapor o citado estudo, agora, ampliando o foco para o exterior, e, consequentemente e a posteriori, vislumbrar análises comparativas entre o âmbito nacional e o internacional.

\section{REFERÊNCIAS}

ALIGICA, P. D. Scenarios and the growth of knowledge: notes on the epistemic element in scenario building. Technological Forecasting \& Social Change, v. 72, p. 815-824, 2005.

AMARANTE, J.; CRUBELLATE, J. M.; MEYER JUNIOR, V. Estratégias em universidades: uma análise comparativa sob a perspectiva institucional. GUAL, v. 10, n. 1, 2017.

AMER, M.; DAIM, T. U.; JETTER, A. A review of scenario planning. Futures, v. 46, p. 23 40, 2013.

AZEVEDO, M. C. de; COSTA, H. G. Métodos para avaliação da postura estratégica. Revista de Gestão da USP, v. 8, n. 2, 2010.

BARNEY, J. Firm resources and sustained competitive advantage. Journal of Management, USA, v. 17, n. 1, p. 99-120, 1991.

BENEDETTI, M.; VIDOR, G. Modelo para análise de capacidade de projetos de pesquisa de uma instituição de ensino superior. Revista Gestão Universitária na América Latina, v. 9, n. 1, p. 278-297, 2016.

BERTERO, C. O.; CALDAS, M. P.; WOOD JR, T. Produção científica em administração de empresas: provocações, insinuações e contribuições para um debate local. RAC, v. 3, n. 1,1999 .

BLANNING, R. W.; REINIG, B. A. Building scenarios for Hong Kong using EMS. Long Range Planning, v. 31, n. 6, p. 900-910, 1998.

BOWMAN, G. The practice of scenario planning: an analysis of inter-and intra-organizational strategizing. British Journal of Management, v. 27, n. 1, p. 77-96, 2016.

BRADFIELD, R.; CAIRNS, G.; WRIGHT, G. Teaching scenario analysis-An action learning pedagogy. Technological Forecasting and Social Change, v. 100, p. 44-52, 2015.

CARDOSO, A. L. J.; KATO, H. T. Análise das publicações sobre capacidades dinâmicas entre 1992 e 2012: discussões sobre a evolução conceitual e as contribuições dos autores de maior notoriedade na área. Revista de Administração Mackenzie, v. 16, n. 3, p. 201-237, 2015. 
CARVALHO, F. de M.; KAYO, E. K.; MARTIN, D. M. L. Tangibilidade e intangibilidade na determinação do desempenho persistente de firmas brasileiras. RAC, v. 14, p. 871-889, 2010 .

CIRANI, C. B. S.; SILVA, H. H. M. da; CAMPANARIO, M. de A. A evolução do ensino da pós-graduação estrito senso em administração no Brasil. RAC, v. 16, n. 6, p. 765-783, 2012.

COORDENAÇÃO DE APERFEIÇOAMENTO DE PESSOAL DE NÍVEL SUPERIOR CAPES. Documento de área: Administração Pública e de Empresas, Ciências Contábeis e Turismo. Disponível em: <http://www.capes.gov.br/>. Acesso em: 16 fev.2019.

COORDENAÇÃO DE APERFEIÇOAMENTO DE PESSOAL DE NÍVEL SUPERIOR CAPES. Proposta de aprimoramento do modelo de avaliação da PG: documento final da Comissão Nacional de Acompanhamento do PNPG 2011-2020 - 10/10/2018. Disponível em: $<$ http://www.capes.gov.br/>. Acesso em: 22 jan.2019.

FRANCO, D. S.; PAIVA, K. C. M. de; HELMOND, S. de C. Possibilidades e desafios para uma abordagem andragógica no ensino em administração e Contabilidade. Revista ADM.MADE, v.19, n.3, p.16-33, 2015.

GHEMAWAT, P. A estratégia e o cenário dos negócios. Porto Alegre: Bookman, 2007.

GODET, M. Future memories. Technological Forecasting and Social Change, v. 77, n. 9, p. 1457-1463, 2010.

GOODWIN, P.; WRIGHT, G. Enhancing strategy evaluation in scenario planning: a role for decision analysis. Journal of Management Studies, v. 38, n. 1, p. 1-16, 2001.

GRANT, R. M. Strategic planning in a turbulent environment: evidence from the oil majors. Strategic Management Journal, v. 24, n. 6, p. 491-517, 2003.

HADDAD, C. R.; CATAPAN, A.; SILVA, F. da; MALDONADO, M. U. Dinâmica de sistemas e prospecção de cenários: uma revisão da literatura. FUTURE, v. 9, n. 3, p. 93-125, 2017.

HEINZEN, D. A. de M. Alinhamento entre formulação e implementação da estratégia em Instituição de Ensino Superior, Tese (Doutorado em Administração e Turismo), Univalí, 2015, 202 pg.

HEINZEN, D. A. de M.; MARINHO, S. V. Alinhamento entre formulação e implementação da estratégia em instituições de ensino superior no Brasil. Organizações em Contexto, v. 15, n. 29, p. 279-322, 2019.

HICKS, D.; GIDLEY, J. Futures education: Case studies, theories and transformative speculations. Futures, v. 44, n. 1, p. 1-3, 2012. 
HODGKINSON, G. P.; HEALEY, M. P. Toward a (pragmatic) science of strategic intervention: Design propositions for scenario planning. Organization Studies, v. 29, n. 3, p. 435-457, 2008.

ITHNIN, F.; SAHIB, S.; ENG, C. K.; SIDEK, S.; HARUN, R. N. S. R. Mappingthe futures of malaysianhigher education: a meta - analysis of futures studies in the Malaysian higher educations cenario. Journal of Futures Studies, v. 22, n. 3, p. 1-18, 2018.

LINDGREN, M.; BANDHOLD, H. Scenario planning. Palgrave, 2003.

MACCARI, E. A. et al. A gestão dos programas de pós-graduação em administração com base no sistema de avaliação da Capes. Revista de Gestão USP, v. 16, n. 4, p. 01-16, 2009.

MACCARI, E. A.; LIMA, M. C.; RICCIO, E. L. Uso do Sistema de Avaliação da CAPES por Programas de Pós-Graduação em Administração no Brasil. RCA, v. 11, n. 25, p. 68-96, 2009.

MACCARI, E. A.; RICCIO, E. L.; MARTINS, C. B. A influência do sistema de avaliação da AACSB na gestão dos programas de pós-graduação stricto sensu em Administração nos Estados Unidos. Revista Eletrônica de Administração, v. 19, n. 3, p. 738-766, 2013.

MAGGS, P.; CHELIN, J. Scenario planning for an uncertain future? Case study of the restructuring of the academic services team at UWE Library. Library Management, v. 34, n. 8/9, p. 664-676, 2013.

MARCIAL, E. C.; GRUMBACH, R. J. S. Cenários prospectivos: como construir um futuro melhor. 4.ed. Rio de Janeiro: Editora FGV, 2002.

MARTINS, C. B. et al. Utilização da Resource Based-View no desempenho dos programas de pós-graduação stricto sensu em administração, ciências contábeis e turismo no Brasil: um estudo dos programas no período de 2001 a 2009. Anais..., EnANPAD,37,Rio de Janeiro, 2013.

MIRANDA, G. J.; CASA NOVA, S. P. de C.; CORNACCHIONE JR, E. B. Ao mestre com carinho: relações entre as qualificações docentes e o desempenho discente em contabilidade. Revista Brasileira de gestão de Negócios, v. 15, n. 48, p. 462-481, 2013.

MOORCROFT, S. Scenario based strategy - Navigate the future. Foresight, v. 17, n. 5, p. 542-542, 2015.

MORITZ, G. de O. et al. A Pós-graduação brasileira: evolução e principais desafios no ambiente de cenários prospectivos. Future Studies Research Journal, v. 5, n. 2, p. 3-34, 2013.

MORITZ, G. de O.; NUNER, R.; PEREIRA, M. F. Os métodos de prospecção de cenários e sua aplicação nas organizações: um estudo de caso no período 1998-2008. Revista de Administração da FACES, v. 7, n. 2, p. 68-83, 2008. 
MORITZ, G. de O.; PEREIRA, M. F. Planejamento de cenários: a evolução do pensamento prospectivo. Revista Ciências da Administração, v. 7, n. 13, p. 1-20, 2005.

MORITZ, M. O. Perspectivas e tendências das universidades públicas gratuitas de Santa Catarina. Dissertação (Mestrado em Administração) - Universidade Federal de Santa Catarina (UFSC), Florianópolis, 2012.

OLIVEIRA, O.; FORTE, S. A indústria bancária brasileira: construindo cenários prospectivos e identificando as estratégias de utilização mais provável. RPBG, p. 64-77, 2009.

OLIVEIRA, O. V. de; FORTE, S. H. A. C. Estratégias e ferramentas competitivas das MPEs na região Nordeste. Revista da Micro e Pequena Empresa, v. 8, n. 2, p. 18-37, 2014.

OLIVEIRA, O. V. de; FORTE, S. H. A. C. Identificação dos recursos competitivos de utilização mais provável pela indústria bancária brasileira de 2008 a 2012. RAUSP, v. 46, n. 3,2011 .

PATRUS, R.; SHIGAKI, H. B.; DANTAS, D. C. Quem não conhece seu passado está condenado a repeti-lo: distorções da avaliação da pós-graduação no Brasil à luz da história da Capes. Cadernos EBAPE. BR, v. 16, n. 4, p. 642-655, 2018.

POLESI, A. Cenários para o Brasil no futuro. Estudos Avançados, v. 20, n. 56, p. 1-7, 2006.

PORTER, M. E. Competitive strategy: techniques for analyzing industries and competitors. New York: Free Press, 1980.

RAM, C.; MONTIBELLER, G.; MORTON, A. Extending the use of scenario planning and MCDA for the evaluation of strategic options. JORS, v. 62, n. 5, p. 817-829, 2011.

RIECKMANN, M. Future-oriented higher education: which key competencies should be fostered through university teaching and learning? Futures, v. 44, n. 2, p. 127-135, 2012.

SANTOS, G. E. de O.; REJOWSKI, M. Comunicação científica em turismo no Brasil: análises descritivas de periódicos nacionais entre 1990 e 2012. RBTUR, v. 7, n. 1, p. 149$167,2013$.

SANTOS, J. E. A. dos; CÂNDIDO, G. A. Estrutura de governança em arranjos produtivos locais: uma aplicação no arranjo calçadista no município de Campina Grande/PB. Anais..., Encontro de Estudos em Estratégia, 4, Bento Gonçalves, 2013.

SAURIN, R.; RATCLIFFE, J. Using an adaptive scenarios approach to establish strategies for tomorrow's workplace. Foresight, v. 13, n. 4, p.46-63, 2011.

SOUSA, J. R. de; FORTE, S. H. A. C.; OLIVEIRA, O. V. de. Recursos estratégicos no cenário 2009/2015 das IESS particulares da região nordeste do Brasil. RIAE, v. 11, p. 91$119,2012$. 
VIEIRA, A. R.; VIANA, A. B. N.; ZABALZA, M. Propostas de melhoria para a formação docente dos programas de pós-graduação stricto sensu em administração. Anais..., XL EnANPAD, Costa do Sauipe, 2016.

WEISS, L. A. S. et al. Cenários: uma análise da produção científica brasileira entre1980 e 2016. Future Studies Research Journal, v. 9, n. 2, p. 116-139,2017.

WERNERFELT, B. A resource-based view of the firm. Strategic Management Journal, v. 5, n. 2, p. 171-180, 1984.

WILKINSON, A.; KUPERS, R.; MANGALAGIU, D. How plausibility-based scenario practices are grappling with complexity to appreciate and address 21 st century challenges. Technological Forecasting and Social Change, v. 80, n. 4, p. 699-710, 2013.

WRIGHT, G.; GOODWIN, P. Decision making and planning under low levels of predictability: Enhancing the scenario method. International Journal of Forecasting, v. 25, n. 4, p. 813-825, 2009. 